\title{
Factors Influencing Client Retention in Methadone Maintenance Treatment Clinics in the Kathmandu Valley
}

\author{
Sapkota $\mathrm{B}^{1}$, Tulachan $\mathrm{P}^{2}$, Ojha $\mathrm{SP}^{3}$, Chapagai $\mathrm{M}^{4}$, Dhungana $\mathrm{S}^{5}$
}

1. Consultant Psychiatrist, Gan Regional Hospital, Ministry of Health, Maldives. 2. Assistant Professor, Department of Psychiatry and Mental Health, Maharajgunj Medical Campus, Kathmandu. 3. Professor, Department of Psychiatry and Mental Health, Maharajgunj Medical Campus, Kathmandu 4. Professor, Department of Psychiatry and Mental Health, Maharajgunj Medical Campus, Kathmandu 5. Assistant Professor, Department of Psychiatry and Mental Health, Maharajgunj Medical Campus, Kathmandu.

E-mail *Corresponding author $: \underline{\text { basantasapkota1970@gmail.com }}$

\begin{abstract}
Introduction: Methadone maintenance treatment program is one of the accepted form of treatment modalities for opioid dependence individuals in Nepal. Retention in the treatment represents the assessment of the effectiveness of the treatment program. The aim of this study was to find out the factors associated with the retention of clients in the Methadone maintenance clinics in the Kathmandu Valley.

Material And Method: A total of 84 clients were recruited from the 5 different methadone clinics of Kathmandu valley. A prospective follow-up design was used. The patients were followed up at the end of 6 months and retention rate was calculated. The patient was considered 'drop out "if the patient did not take methadone for 7 consecutive days. Group differences between 'dropout' and non-dropout (retained) clients on MMT program were tested using $t$-test and Chi-square test for continuous variables and categorical variables respectively.
\end{abstract}

Results: At the end of 6 months 63 patients still remained in the MMT program, so the retention rate was found to be $75 \%$ in the study. The factors associated with the retention included higher dosage of methadone $(p<0.001)$, history of multiple substance intake $(p=0.004)$ and previous treatment history of the drug related problems $(p=0.015)$.

Conclusion: Opioid dependent individuals may stick to the MMT program for longer durtion if they are offered with higher dosage of Methadone and special attention should be given to the patients with history of poly substance abuse and prior treatment history to prevent their relapse.

Keywords: Methadone, Retention rate, Methadone maintenance Treatment Program

\section{INTRODUCTION}

Dole and Nyswander introduced Methadone Maintenance Treatment (MMT) for the Heroin addicts in the mid 1960s in the United States. Since then, MMT has become the most extensively adopted program for the opioid dependence throughout the world. Nepal too initiated the MMT program in 1994 which was closed due to several reasons in 2002 and was re-introduced in 2007 as an emergency response to HIV prevention. ${ }^{1}$ Now, MMT program has been extended to different cities of Nepal such as Pokhara, Butwal, and Dharan including five in Kathmandu valley.

With the popularity of MMT program worldwide, vast studies have been done in the field of methadone and it has become most commonly evaluated form of treatment for drug abuse. There has been burgeoning evidence of overall effectiveness of MMT compared to other modalities of treatment such as outpatient counseling and detoxification. Several studies have found that enrolment in methadone maintenance treatment program is associated 
with significant reduction in various types of criminal activities. ${ }^{2-4}$ In recent decade, there has been growing evidence that methadone maintenance treatment (MMT) is associated with a significant decrease in both drug- and sex-related risk behaviors among this high-risk population. ${ }^{5-7}$ Similarly, MMT has been associated with improved physical and mental health status, social and occupational functioning and quality of life of the opioid dependent individuals who are enrolled in this program. ${ }^{8-11}$

One of the crucial primary outcome measures included in research studies is retention in MMT program. And, it is considered critical in the evaluation of treatment effectiveness because longer retention is associated with reduction on relapse to drug use and high-risk behaviors, mortality rates and better functioning in society. Therefore, it is important that MMT programs exhibit decreased drop-out rates compared to other treatment options. Previous systematic reviews and metanalysis around the globe have found varying percentage of retention in MMT program from $40 \%$ to $90 \% .{ }^{12-14}$ Similarly, the patient characteristic such as age and sex, ${ }^{15-}$ ${ }^{17}$ employment $\quad$ status, ${ }^{18}$ methadone dose, ${ }^{18-}$ ${ }^{20}$ criminal history, ${ }^{15}$ society ${ }^{16}$ and peer support ${ }^{19}$ have been identified in prior studies as crucial factors in predicting the likelihood of continuation of treatment for longer duration. Though, MMT program is being operated for more than a decade in Nepal, the research in this field is sparse. Dangol, Chapagain, and Tulachan studied on treatment compliance among methadone clients on MMT program in TUTH, Nepal and found that the lower the doses of methadone higher the drop out from the Methadone Maintenance Treatment Program.21 Another, study by Sharma, Chamroonswasdi, and Srisorrachatr showed that $72.1 \%$ of respondents had good adherence to MMTP program and clients without a previous history of relapse were 2.7 times more likely to adhere to the MMTP than those with a history of relapse and respondents with a good knowledge of the MMTP were 9.4 times more likely to be adherent to the MMTP than those with a poor to fair knowledge of MMTP. ${ }^{22}$ These studies have not provided the sufficient information on the effectiveness of MMT program in Nepal. So, this study was carried out to find out the retention rate and factors affecting it which will help to gauge the efficacy of the MMT program in Kathmandu, Nepal.

\section{MATERIAL AND METHOD}

This prospective follow-up study was conducted in three districts of Kathmandu Valley. A total of 84 patients were selected by purposive sampling Method from the clients visiting in the five Methadone Maintenance Treatment Clinics of Kathmandu valley. The study duration was from May 2016 to October 2016. The inclusion criteria were all Opioid dependent individuals (aged18-65), who met the ICD-10 (F11) criteria and were newly enrolled in the outpatient methadone maintenance program and were willing to undergo follow-up assessment at 6 months. Those with co-morbid psychiatric disorders such as schizophrenia, delusional disorder, other anxiety disorders and mood disorders were excluded on the basis of clinical interview. An informed consent was taken from the participants and self designed semi-structured pro-forma was used to collect information about socio-demographic profile and details of substance taking history and associated factors of the clients. All the clients who participated in the study were followed up for 6 month and the date of the clients who dropped out was recorded. The patient was considered 'drop out "if the patient did not take methadone for 7 consecutive days. ${ }^{23} \mathrm{At}$ the end of the study period, retention rate and factors associated with it were calculated. Group differences between 'dropout' and non dropout clients on MMT program were tested using t-test and Chi-square test for continuous variables and categorical variables respectively. The predictor variables were age, sex, marital status, educational status, and occupation, type of family, past history of treatment, history of medical illness, prison history, and average dosage of methadone and polysubstance abuse. Data were analyzed using Statistical Package for Social Sciences (SPSS), Inc., and Chicago, Illinois, USA version 17 for Windows. The differences between the groups were considered significant if the p-value were less than 0.05 . 


\section{RESULT}

Table 1 shows the comparison of sociodemographic characteristics between drop outs and non drop out from the MMT program. Among the total 84 patients, 81 of them were male and 3 were female. The age of the subjects joining the MMT program was variable and majority was from age group 25 to 30.Thity three percent of them were married and most of them (69\%) had full time employment. Maximum number of the subjects had obtained higher secondary degree and mostly they were from nuclear family. At the end of six months, twenty-five percent of the patient i.e. 21 (20 male and 1 female) out of $84(25 \%)$ dropped out from the treatment program. There was no statistically significant difference in terms of age ( $p$ value $=0.893)$, and occupation ( $p$ value $=0.883$ ) between drop outs and non dropouts. Similarly, the difference in the drop-out rate between employed and unemployed was insignificant $(p$ value $=0.785$ ). Likewise, past history of being in police custody $(p=0.371)$ did not affect the retention of the clients in the MMT program. However, there was statistically significant difference between the drop outs and non drop out in terms of past history of drug treatment $(p=0.015)$, i.e. having past history of drug treatment is associated with higher drop outs. In addition to it, clients taking polysubstance: alcohol, cannabis, heroin, injectables and other opioids and benzodiazepines ( $p$ value $=0.047$ ) had poor adherence to the MMT program. Likewise, the clients who dropped out were taking on average $17.05 \pm 5.83 \mathrm{mg}$ of methadone while who did not drop out were taking $43.25 \pm 12.42 \mathrm{mg}$ of methadone(Table 2). So the clients taking lower doses had greater dropout rate than clients taking higher doses ( $\mathrm{p}$ value $<0.001)$.

Table 1: Comparison of the differences of demographic characteristics, past history of treatment and drug use patterns of dropouts and non-drop outs

\begin{tabular}{|c|c|c|c|c|}
\hline Characteristics & $\begin{array}{c}\text { Dropout } \\
(n=21)\end{array}$ & $\begin{array}{c}\text { Non } \\
\text { dropout } \\
(n=63)\end{array}$ & $\begin{array}{l}\text { Total } \\
(\mathrm{n}=84)\end{array}$ & $\begin{array}{c}\text { P- } \\
\text { value }\end{array}$ \\
\hline Age & 22.4 & 35.8 & 29.1 & 0.738 \\
\hline \multicolumn{5}{|l|}{ Sex } \\
\hline Male & $20(95.24)$ & $61(96.82)$ & 81 & \\
\hline Female & $1(4.76)$ & $2(3.18)$ & 3 & \\
\hline \multicolumn{5}{|l|}{ Marital Status } \\
\hline Single & 12(57.14) & $37(58.74)$ & 49 & \\
\hline Married & $7(33.34)$ & $21(33.33)$ & 28 & \\
\hline Separated & $1(4.76)$ & $4(6.34)$ & 5 & \\
\hline Widowed & $1(4.76)$ & 1(1.59) & 2 & \\
\hline \multicolumn{5}{|l|}{$\begin{array}{l}\text { Educational } \\
\text { status }\end{array}$} \\
\hline University & $0(0.00)$ & $10(15.88)$ & 10 & \\
\hline $\begin{array}{l}\text { Higher } \\
\text { secondary }\end{array}$ & $5(23.80)$ & $25(39.69)$ & 29 & \\
\hline Secondary & $8(38.09)$ & $15(23.80)$ & 23 & \\
\hline Primary & $4(19.06)$ & $7(11.12)$ & 11 & \\
\hline $\begin{array}{l}\text { Can read and } \\
\text { write }\end{array}$ & $3(14.29)$ & $5(7.94)$ & 8 & \\
\hline Illiterate & $1(4.76)$ & $2(3.17)$ & 3 & \\
\hline \multicolumn{5}{|l|}{ Occupation } \\
\hline Employed & $15(71.42)$ & $43(68.25)$ & 58 & 0.833 \\
\hline Unemployed & $6((28.58)$ & $20(31.75)$ & 26 & \\
\hline \multicolumn{5}{|l|}{ Type of Family } \\
\hline Nuclear & $8(38.09)$ & $36(57.15)$ & 44 & \\
\hline Joint & $12(57.15)$ & $26(41.26)$ & 38 & \\
\hline Broken & $1(4.76)$ & $1(1.59)$ & 2 & \\
\hline \multicolumn{5}{|l|}{ Chronic illness } \\
\hline Yes & $1(4.16)$ & 12(19.04) & 13 & \\
\hline No & $20(95.84)$ & $51(80.96)$ & 71 & \\
\hline \multicolumn{5}{|l|}{ Police custody } \\
\hline Yes & $14(66.67)$ & $35(55.55)$ & 49 & 0.317 \\
\hline No & $7(33.33)$ & $28(44.44)$ & 55 & \\
\hline \multicolumn{5}{|l|}{$\begin{array}{l}\text { Past history of } \\
\text { drug treatment }\end{array}$} \\
\hline Yes & $17(80.94)$ & $32(50.79)$ & 49 & 0.015 \\
\hline No & $4(19.06)$ & $31(49.21)$ & 35 & \\
\hline \multicolumn{5}{|l|}{$\begin{array}{l}\text { Type of } \\
\text { Substance } \\
\text { taken }\end{array}$} \\
\hline Heroin only & $6(28.57)$ & $6(9.52)$ & 12 & 0.004 \\
\hline Polysubstance & $15(71.43)$ & $57(90.48)$ & 52 & \\
\hline
\end{tabular}

Table 2: Comparison of dosages of methadone between dropouts and non dropouts

\begin{tabular}{|l|c|c|c|}
\hline Variable & \multicolumn{2}{|c|}{ Dropout } & P-value \\
\hline & Yes (n= 21) & No (n=63) & \\
\hline $\begin{array}{l}\text { Dosages of } \\
\text { methadone } \\
(\mathrm{mg})\end{array}$ & $17.05 \pm 5.83$ & $43.25 \pm 12.42$ & $<0.001$ \\
\hline
\end{tabular}




\section{DISCUSSION:}

Seventy five percent of our clients had good adherence to the MMT program in our study. However, retention rate of the clients in the MMT program for 6 months is variable in different studies done worldwide. The rate of adherence in our study is lower than the study done by Phallyka et.al in Cambodia where it was found to be $80.2 \%$ for 6 months. ${ }^{24}$ However, it is higher than the findings of Mohamad et al. in Malaysia and Sarasvita et.al in Indonesia, who concluded that at the end of 6 months 54.6925 and $61.3 \% 26$ of clients respectively remained in the treatment program. In China, Liang et al. revealed that after 6 months, $68.8 \%$ of the patients were still enrolled in the MMT program which decreased to $57.4 \%$ at the end of 12 months. ${ }^{27}$ Our finding is comparable to the findings of Che $\mathrm{Y}$ et al. who had shown that the chance of being retained in the treatment program to be $94 \%$ at 1 month, $75 \%$ at 3 months and $57 \%$ at 6 months. ${ }^{28}$ Similarly, Mutch and bell found that the cumulative probability of retention at 3 months, 6 months and 1 year were $65 \% .51 \%$ and $38 \%$ respectively. ${ }^{29}$ The possible differences in political and socio-economic structure, policy of the methadone clinics, drug use pattern and conditions and service organisation may explain the variations of retention rates among different studies. Furthermore, stigma related to the Methadone intake may influence the adherence to the treatment program.

In this study, significant factors associated with the drop out from the MMT program were lower doses of methadone, poly substance use and prior history of treatment for substance related problems. The dropout groups were taking 17.05 grams of methadone while nondropout groups were taking 43.25 on average. Higher doses of methadone was associated with prolonged retention in treatment, which was replicated in previous studies. ${ }^{15,19,30}$ A review of 44 methadone programs by Joseph et.al concluded that the dose level was the single most important factor affecting adherence in treatment. $^{31}$ D'Ippoliti et.al's study among methadone clients highlighted that methadone dose is a critical factor in retaining patients in treatment. ${ }^{12} \mathrm{His}$ findings was similar to Ward et. al's who showed that higher doses consistently encourage treatment retention and reductions in illicit drug use in MMT. ${ }^{32}$ Numerous prior studies including ours has found that higher doses of methadone improve the retention and outcome, so adequate clinical dosages of methadone after stabilization are important for maintaining patients in treatment and that recommended guidelines should be considered. Poly substance abuse was another notable predictor of dropout in our study. History of polysubstance abuse was associated with higher dropout from the MMT program. The finding is similar to the research of Pashaei et. al where it was shown that patients who were polysubstance dependents were at much higher risk of relapse. ${ }^{33}$ Many previous studies have found that patient who are mixed drug users were more likely to quit the tretment program ${ }^{34-36}$ Our finding was in contrast to the finding by Fatollahi et. al in Iran who revealed that patients who abused polysubstances are more likely to remain in treatment at one year compared to those who abused a single substance before entering MMT. ${ }^{24}$ The reason for the dropout of polysubstance users in our context may be due to the fact that most of the opioid users are abusing benzodiazepines simultaneously, as methadone does not eliminate the craving and withdrawal features of benzodiazepines they may drop drop out from the program and end up relapsing.Further study is needed to find the role of benzodiazepine withdrawal features as the cause of relpase of the clients in the MMT program.

Prior treatment history predicted the lower retention in the MMT program in this study. This finding is similar to the result of Pashaei et al. in Iran, who found that prior treatment shortened treatment retention. ${ }^{33}$ However, this relation between the previous treament history and lower retention is not consitent in studies done before. While research by Dennis et al.had demonstrated negative association between history of treatment and retention rate, ${ }^{37}$ study by Hser et al. had shown the reverse. ${ }^{38}$ Unsuccessful treament history might dampen the self-esttem and self-efficacy of opioid dependent individuals, which can make them vulnerable to relapse. In terms of socio demographic profile, Common age group who were enrolled in the program were from $20-30(\mathrm{~N}=41,48.80 \%)$, and dropout rate was also high in same age group, though it 
was not statistically significant. Several studies have shown that age consistently predicts treatment duration, where older clients are more likely to remain in treatment longer than younger clients. Older clients usually are parents with added responsibility, who may want their life to be stable; also they may get tired of their chaotic life of drug dependence, so they stick to the treatment program instead of dropping

out. Our study cound not find the association of other socio demographic characteristics such as gender, employment status, education, marital status, religion, ethnicity in the retention of the clients in the MMT program. Although some prior studies have found some correlation between these factors and the drop out from the treatment program, the small sample size of our study might have prevented us from finding any association. There were several limitations of the study. Firstly, we could not analyze the role of important factors such as clinic policy, social and family support as the cause of the relapse. Secondly, the result of this study cannot be generalized due to the small sample size and the study was conducted in the capital city with homogenous population. So, the result of this study should be interpreted with caution. Thirdly, the patients were followed up just for 6 months after enrolment, so the longer- term retention rate of the program could not be revealed. Hence, further study is needed find the long term fate of clients' who are enrolled in MMT program in Nepal.

\section{CONCLUSION:}

Dosage of the methadone, prior treatment history and multiple substance abuses can affect the retention of the patient in the MMT program. So we suggest higher methadone dosage for the patients, when appropriate, to prevent the drop out of the patients from methadone clinics. Moreover, knowledge of these factors may help to identify the subgroup of patients who are vulnerable to relapse and may need special considerations.

ACKNOWLEDGEMENT: We would like to thank all the staffs of the Methadone Maintenance Clinics of Kathmandu Valley for their invaluable assistance throughout the study. Also, the cooperation of all the participants is highly appreciated.

\section{FUNDING: None}

\section{CONFLICT OF INTEREST: None}

\section{REFERENCES:}

1. Ambekar A, Rao R, Pun A, Kumar S, Kishore K. The trajectory of methadone maintenance treatment in Nepal. International Journal of Drug Policy. 2013;24(6):e57-e60.

2. Bell J, Hall W, Byth $K$. Changes in criminal activity after entering methadone maintenance. British journal of addiction. 1992;87(2):251-8.

3. Rothbard A, Alterman A, Rutherford M, Liu F, Zelinski S, McKay J. Revisiting the effectiveness of methadone treatment on crime reductions in the 1990s. Journal of Substance Abuse Treatment. 1999;16(4):329-35.

4. Bell J, Mattick R, Hay A, Chan J, Hall W. Methadone maintenance and drug-related crime. Journal of Substance Abuse. 1997;9:15-25.

5. Otiashvili D, Piralishvili G, Sikharulidze Z, Kamkamidze G, Poole S, Woody GE. Methadone and buprenorphine-naloxone are effective in reducing illicit buprenorphine and other opioid use, and reducing HIV risk behavior-outcomes of a randomized trial. Drug and alcohol dependence. 2013;133(2):376-82.

6. Marsch LA. The efficacy of methadone maintenance interventions in reducing illicit opiate use, HIV risk behavior and criminality: a meta-analysis. Addiction. 1998;93(4):515-32.

7. Millson P, Challacombe L, Villeneuve PJ, Strike CJ, Fischer B, Myers T, et al. Reduction in InjectionRelated HIV Risk After 6 Months in a Low-Threshold Methadone Treatment Program. AIDS Education and Prevention. 2007;19(2):124-36.

8. Chou Y-C, Shih S-F, Tsai W-D, Chiang-shan RL, Xu $K$, Lee TS-H. Improvement of quality of life in methadone treatment patients in northern Taiwan: a follow-up study. BMC psychiatry. 2013;13(1):190.

9. McLellan AT, Arndt IO, Metzger DS, Woody GE, O'Brlen CP. The Effects of Psychosocial Services in Substance Abuse Treatment. Addictions Nursing Network. 1993;5(2):38-47.

10. De Maeyer J, Vanderplasschen W, Broekaert E. Quality of life among opiate-dependent individuals: A review of the literature. International journal of drug policy. 2010;21(5):364-80.

11. Schreiber S, Peles E, Adelson M. Association between improvement in depression, reduced benzodiazepine (BDZ) abuse, and increased psychotropic medication use in methadone maintenance treatment (MMT) patients. Drug and Alcohol Dependence. 2008;92(1):79-85. 
12. D'Ippoliti D, Davoli M, Perucci CA, Pasqualini F, Bargagli AM. Retention in treatment of heroin users in Italy: the role of treatment type and of methadone maintenance dosage. Drug and Alcohol Dependence. 1998;52(2):167-71.

13. Timko C, Schultz NR, Cucciare MA, Vittorio L, Garrison-Diehn C. Retention in medication-assisted treatment for opiate dependence: A systematic review. Journal of Addictive Diseases. 2016;35(1):22-35.

14. Zhang L, Chow EPF, Zhuang X, Liang Y, Wang Y, Tang $C$, et al. Methadone Maintenance Treatment Participant Retention and Behavioural Effectiveness in China: A Systematic Review and Meta-Analysis. PLOS ONE. 2013;8(7):e68906.

15. Kelly SM, O'Grady KE, Mitchell SG, Brown BS, Schwartz RP. Predictors of methadone treatment retention from a multi-site study: A survival analysis. Drug and Alcohol Dependence. 2011;117(2):170-5.

16. Strike CJ, Gnam W, Urbanoski K, Fischer B, Marsh DC, Millson M. Factors predicting 2-year retention in methadone maintenance treatment for opioid dependence. Addictive Behaviors. 2005;30(5):1025-8.

17. Liang T, Liu E-w, Zhong H, Wang B, Shen L-m, Wu $Z-l$. [Factors influencing the rate on retention to methadone maintenance treatment program among heroin addicts in Guizhou, China]. Zhonghua Liu Xing Bing Xue Za Zhi. 2009;30(2):131-5.

18. Schiff M, Levit S, Moreno RC. Retention and illicit drug use among methadone patients in Israel: A gender comparison. Addictive Behaviors. 2007;32(10):210819.

19. Booth RE, Corsi KF, Mikulich-Gilbertson SK. Factors associated with methadone maintenance treatment retention among street-recruited injection drug users. Drug and Alcohol Dependence. 2004;74(2):177-85.

20. Deck DC, M.J. Retention in publicly funded methadone maintenance treatment in two western states. The Journal of Behavioral Health Services \& Research 2005;32(43).

21. Dongol.k.M.Chapagain.Tulachan.P. A study on Treatment Compliance among Methadone Clients in MMTP Program TUTH,Nepal. Journal of Nobel Medical College. 2013;2(2):50-6.

22. V.Sharma, K.Chamroonswasdi, S.Srisorrachatr. Rate of Adherence to and Factors Associated with Methadone Maintenance Treatment Program (Mmtp) Compliance among Injecting Drug Use. Southeast Asian Journal of Tropical Medicine and Public Health. 2016;47(2):287.

23. Liu E, Lee V, Wong L-c, Secretariat LC. Methadone Treatment Programmes in the United States: Research and Library Services Division, Legislative Council Secretariat; 1996.

24. Fathollahi MS, Torkashvand F, Najmeddin $H$, Rezaeian M. Predictors of one-year retention in methadone maintenance treatment (MMT) in Iran, Rafsanjan. International journal of high risk behaviors $\mathcal{E}$ addiction. 2016;5(3).

25. Mohamad N, Bakar NH, Musa N, Talib N, Ismail R. Better retention of Malaysian opiate dependents treated with high dose methadone in methadone maintenance therapy. Harm reduction journal. 2010;7(1):30.

26. Sarasvita R, Tonkin A, Utomo B, Ali R. Predictive factors for treatment retention in methadone programs in Indonesia. Journal of substance abuse treatment. 2012;42(3):239-46.

27. Wang R, Ding Y, Bai H, Duan S, Ye R, Yang Y, et al. Illicit heroin and methamphetamine use among methadone maintenance treatment patients in Dehong Prefecture of Yunnan Province, China. PloS one. 2015;10(7):e0133431.

28. Che Y, Assanangkornchai S, McNeil E, Chongsuvivatwong V, Li J, Geater A, et al. Predictors of early dropout in methadone maintenance treatment program in Yunnan province, China. Drug and alcohol review. 2010;29(3):263-70.

29. Bell J, Bell J, Mutch C. Treatment retention in adolescent patients treated with methadone or buprenorphine for opioid dependence: a file review. Drug and alcohol review. 2006;25(2):167-71.

30. Farré M, Mas A, Torrens M, Moreno Vc, Cami J. Retention rate and illicit opioid use during methadone maintenance interventions: a meta-analysis. Drug and alcohol dependence. 2002;65(3):283-90.

31. Joseph H, Stancliff $S$, Langrod J. Methadone maintenance treatment (MMT): a review of historical and clinical issues. The Mount Sinai Journal of Medicine, New York. 1999;67(5-6):347-64.

32. Ward J, Hall W, Mattick RP. Role of maintenance treatment in opioid dependence. The Lancet. 1999;353(9148):221-6.

33. Pashaei T, Moeeni M, moghdam BR, Turner NE. Predictors of treatment retention in a major methadone maintenance treatment program in Iran: a survival analysis. Journal of research in health sciences. 2014;14(4):291-5.

34. Hiltunen AJ, Eklund C. Withdrawal from Methadone Maintenance Treatment. European Addiction Research. 2002;8(1):38-44.

35. Joe GW, Simpson DD, Broome KM. Retention and patient engagement models for different treatment modalities in DATOS. Drug and Alcohol Dependence. 1999;57(2):113-25.

36. Shah NG, Galai N, Celentano DD, Vlahov D, Strathdee SA. Longitudinal predictors of injection cessation and subsequent relapse among a cohort of injection drug users in Baltimore, MD, 1988-2000. Drug and Alcohol Dependence. 2006;83(2):147-56.

37. Dennis ML, Scott CK, Funk R, Foss MA. The duration and correlates of addiction and treatment careers. Journal of Substance Abuse Treatment. 2005;28(2, Supplement):S51-S62.

38. Hser Y-I, Grella CE, Hsieh S-C, Anglin MD, Brown BS. Prior treatment experience related to process and outcomes in DATOS. Drug and Alcohol Dependence. 1999;57(2):137-50. 